\title{
Probabilistic soil moisture projections to assess Great Britain's future clay-related subsidence hazard
}

\author{
O. G. Pritchard ${ }^{1}$ • S. H. Hallett ${ }^{1}$ - T. S. Farewell ${ }^{1}$
}

Received: 30 April 2015 / Accepted: 10 August 2015 / Published online: 5 September 2015

(C) The Author(s) 2015. This article is published with open access at Springerlink.com

\begin{abstract}
Clay-related subsidence is Great Britain's (GB) most damaging soil-related geohazard, costing the economy up to $£ 500$ million per annum. Soil-related geohazard models based on mineralogy and potential soil moisture deficit (PSMD) derived from historic weather data have been used in risk management since the 1990s. United Kingdom Climate Projections (UKCP09) suggest that regions of GB will experience hotter, drier summers and warmer, wetter winters through to 2050. As a result, PSMD fluctuations are expected to increase, exacerbating the shrinkage and swelling of clay soils. A forward-looking approach is now required to mitigate the impacts of future climate on GB's built environment. We present a framework for incorporating probabilistic projections of PSMD, derived from a version of the UKCP09 stochastic weather generator, into a clay subsidence model. This provides a novel, national-scale thematic model of the likelihood of clay-related subsidence, related to the top 1-1.5 $\mathrm{m}$ soil layer, for three time periods; baseline (1961-1990), 2030 (2020-2049) and 2050 (2040-2069). Results indicate that much of GB, with the exception of upland areas, will witness significantly higher PSMDs through to the 2050s. As a result, some areas with swelling clay soils will be subject to proportionately increased subsidence hazard. South-east England will likely incur the highest hazard exposure to clay-related subsidence through to 2050. Potential impacts include increased incidence of property foundation subsidence, alongside deterioration and increased failure rates of GB's infrastructure networks. Future clay-subsidence hazard scenarios are beneficial to many sectors, including: finance, central and local government, residential property markets, utilities and infrastructure operators.
\end{abstract}

Electronic supplementary material The online version of this article (doi:10.1007/s10584-015-1486-z) contains supplementary material, which is available to authorized users.

S. H. Hallett

s.hallett@cranfield.ac.uk

1 Cranfield Soil and Agrifood Institute, School of Energy, Environment and Agrifood, Cranfield University, Cranfield, UK 


\section{Introduction}

Clay-related subsidence is the most damaging soil-related geohazard in Great Britain (GB; England, Scotland and Wales) costing up to $£ 500$ million per annum (Forster and Culshaw 2004; Pugh 2002). Here we define a geohazard as an environmental phenomenon capable of causing harm to both life and the built environment. Clay-related subsidence or heave results from specific clay soils shrinking and swelling, responding to wetting and drying conditions, respectively (Corti et al. 2011). This leads to vertical and horizontal ground movement, caused by volumetric change in soil mass, which can cause significant damage to infrastructure and property founded within the soil. The susceptibility to which clay soils shrink and swell is controlled by their mineralogy and seasonal moisture flux (Reeve and Hall 1978). It is the magnitude and frequency of this seasonal moisture flux, or potential soil moisture deficit (PSMD), which governs the damaging nature of clay-related shrink-swell cycles. PSMD reflects the balance in flux between rainfall, potential evapotranspiration (PET) and drainage, high PSMD values characterising drier soils and low values wetter soils. PSMD is key to modelling clay-related subsidence. However, unlike acute geohazards (e.g., flooding and landslides), impacts from clay-related shrinkage and swelling are chronic processes, with PSMD developing over many months or seasons (Corti et al. 2011).

Ground movement, incorporating clay-related subsidence, is a recognised hazard to GB's built environment (Cabinet Office 2011). We previously identified impacts of clay-related subsidence on UK infrastructure networks, including pipe and shallow foundation failure, road instability, and potential embankment instability (Pritchard et al. 2014, 2015). The United Kingdoms' (UK) Climate Change Risk Assessment anticipates increased susceptibility of the built environment to ground-related subsidence given future climate projections (Defra 2012; Jenkins et al. 2009). Therefore, anticipating future spatio-temporal trends of this geohazard has the potential to advance geohazard modelling and awareness (Royse 2011). Geohazard information is valuable to both public and private sectors, with its increasing availability driven by HM government planning policy and the insurance industry (Royse 2011). Sectors using geohazard information include: finance, central and local government, residential property markets, utilities and infrastructure operators.

The UK Climate Projections 2009 (UKCP09), based upon a large perturbed physics ensemble (PPE) of the Met Office Hadley Centre's HadCM3 GCM, represent the UK's first probabilistic assessment of climate change for the 21st century, providing a sample of possible climatic changes, incorporating inherent climatic uncertainty. Importantly, UKCP09 provides results not dissimilar to specific climate models (Burton et al. 2010). UKCP09 climate projections suggest that parts of the UK will be subject to increasingly hotter, drier summers and warmer, wetter winters through to 2080 (Jenkins et al. 2009). Soil moisture levels are thus predicted to decrease by $20-40 \%$ in the south-east of England (Sanders and Phillipson 2003), causing marked changes to the spatio-temporal patterns of clay-related subsidence.

Shrinkable clay soils in wetter regions, having low PSMDs, currently exhibit low to medium subsidence potential, yet such areas may face increased subsidence potential under hotter, drier climate scenarios. It is likely that in these areas, previously unaffected by clayrelated subsidence, appropriate mitigation measures will be lacking (e.g., deeper foundations or more flexible material for buried utilities). This was observed in areas of France where the incidence of several years of extreme drought resulted in widespread soil subsidence causing extensive damage, with costs exceeding those of flooding (Corti et al. 2011). Conversely, areas having long-standing incidence of subsidence often have local practitioners (e.g., planners, 
developers, etc.) with both experience and expertise in the adaptation and mitigation of such geohazards (Brook and Marker 2008).

Great Britain clay subsidence models have traditionally been based upon historical, empirical climate data. A number of studies argue qualitatively that UKCP09 projections suggest an increase in clay-related subsidence hazard for specific areas of GB (e.g., Forster and Culshaw 2004; Sanders and Phillipson 2003; Rawlins et al. 2013). UKCP09 is accompanied by a weather generator (WG) providing downscaled, $5 \mathrm{~km}^{2}$ gridded climate projections, encompassing a range of climate variables. The WG is based upon a stochastic process, calibrated to the present day climate, providing statistically plausible realisations of daily climate (Borgomeo et al. 2014). The adoption of the WG and UKCP09 climate projections in climate change risk assessments and applications is well-established in other disciplines; for example, concerning the implications for water resources planning (Christierson et al. 2012; Borgomeo et al. 2014), agricultural risk planning (Knox et al. 2010), geomorphological modelling (Coulthard et al. 2012) and building overheating studies (Jenkins et al. 2014). Nonetheless, few studies incorporate probabilistic projections of climate into soil geohazard models, and none have attempted a national-scale assessment to date. Blenkinsop et al. (2010) fused UKCP09 climate projections with soils data to estimate clay-subsidence hazard for south-east London based upon modelled annual mean PSMD. Similarly, Harrison et al. (2012) applied the earlier UKCIP02 projections to model shrink-swell in bedrock and superficial geology for the south-east of England. For the latter, UKCIP02 projections were chosen over UKCP09 due to resolution and formatting issues at the time of the study. Clarke and Smethurst (2010) used UKCIP02 projections to assess the impact of climate change on infrastructure embankment stability. However, the examples presented by Harrison et al. (2012) and Clarke and Smethurst (2010) are at relatively low resolution $\left(25 \mathrm{~km}^{2}\right.$ grid cells), being deemed unsuitable for understanding local and regional climatic changes.

Our aim was to develop medium-high resolution $\left(5 \mathrm{~km}^{2}\right)$ UKCP09-derived projections of PSMD for GB over three time periods: baseline (1961-1990), 2030 (2020-2049) and 2050 (2040-2069). The approach incorporated these PSMD data within a clay subsidence model for GB only, soil data for Northern Ireland being unavailable for this study. Projections of the spatial and temporal likelihood of clay-related subsidence for all three time periods are presented. Section 2 explores the materials and methodological approach used to process and incorporate UKCP09 climatic projections into an existing soil-related geohazard model. Section 3 presents the results of the climatic modelling for the three scenarios, describing the future soil moisture fluxes (PSMD) and the changing clay-related subsidence geohazard susceptibility for GB. Finally, Section 4 discusses the findings and implications of this research, offering conclusions and suggestions for future study.

\section{Materials and methods}

The methodology presented demonstrates how probabilistic climate information can be applied to long-term assessment of clay-related geohazard potential. A modified version of the UKCP09 stochastic WG was used to derive projections of daily rainfall and PET. These values were processed, providing probabilistic PSMD values for the three time periods; the methodology is summarised in Fig. 1. PSMD scenarios, incorporating climatic uncertainty, were subsequently intersected spatially with soil data and reclassified using an existing geohazard model to ascertain clay-subsidence hazard (Fig. 1). 


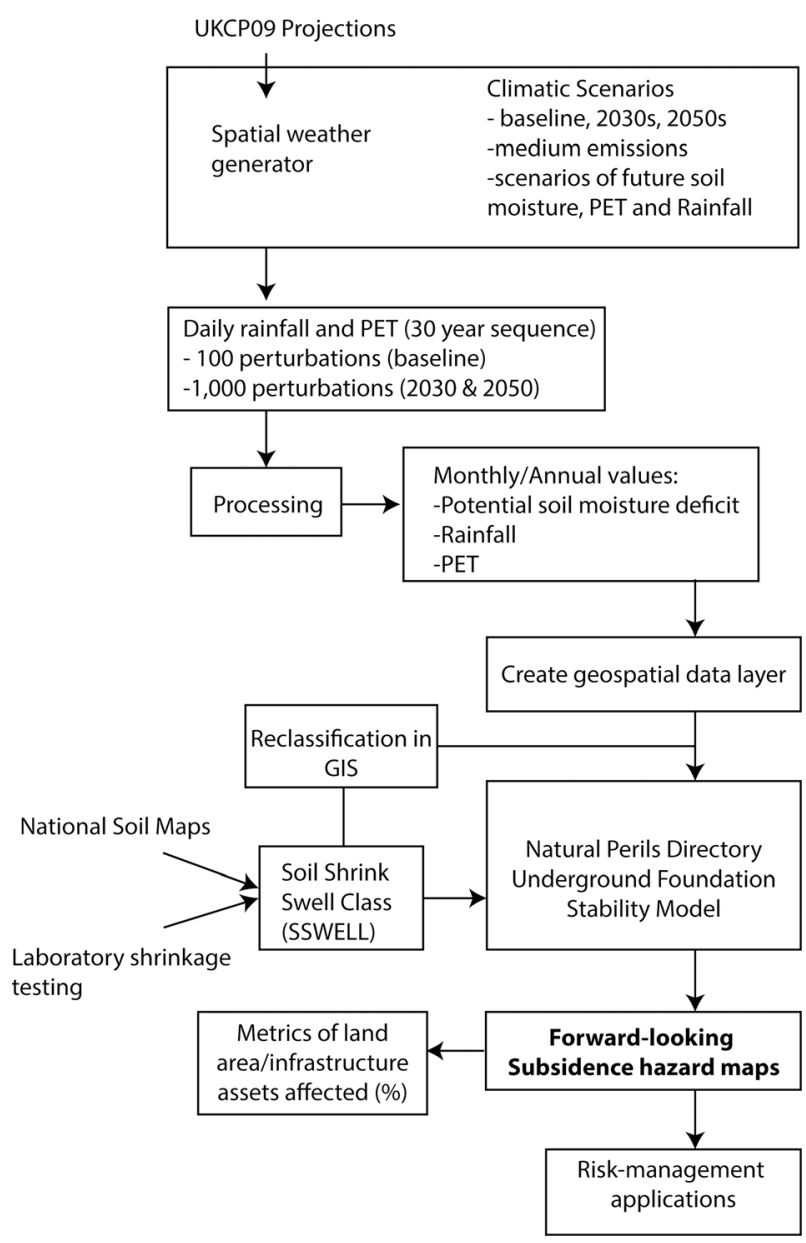

Fig. 1 Methodological framework

This paper's methodology focuses principally upon modelling the hazard (extent, severity and probability) that clay-related subsidence presents. However, in order to present a risk, the built environment needs to be both exposed to the physical geohazard (i.e., clay-related subsidence), as well as being vulnerable to damage (i.e., shallow foundation). This is best represented by the following function, after (Crichton 2001):

$$
\text { Risk }=\int(\text { exposure, hazard, vulnerability) }
$$

The methodological approach is discussed in detail for the remainder of Section 2 below.

\subsection{Natural perils directory}

Since the early 1990s, a range of spatial soil-related geohazard models have been developed for GB (e.g., Hallett et al. 1994). The Natural Perils Directory ${ }^{\mathrm{TM}}$ (NPD) is a geohazard 


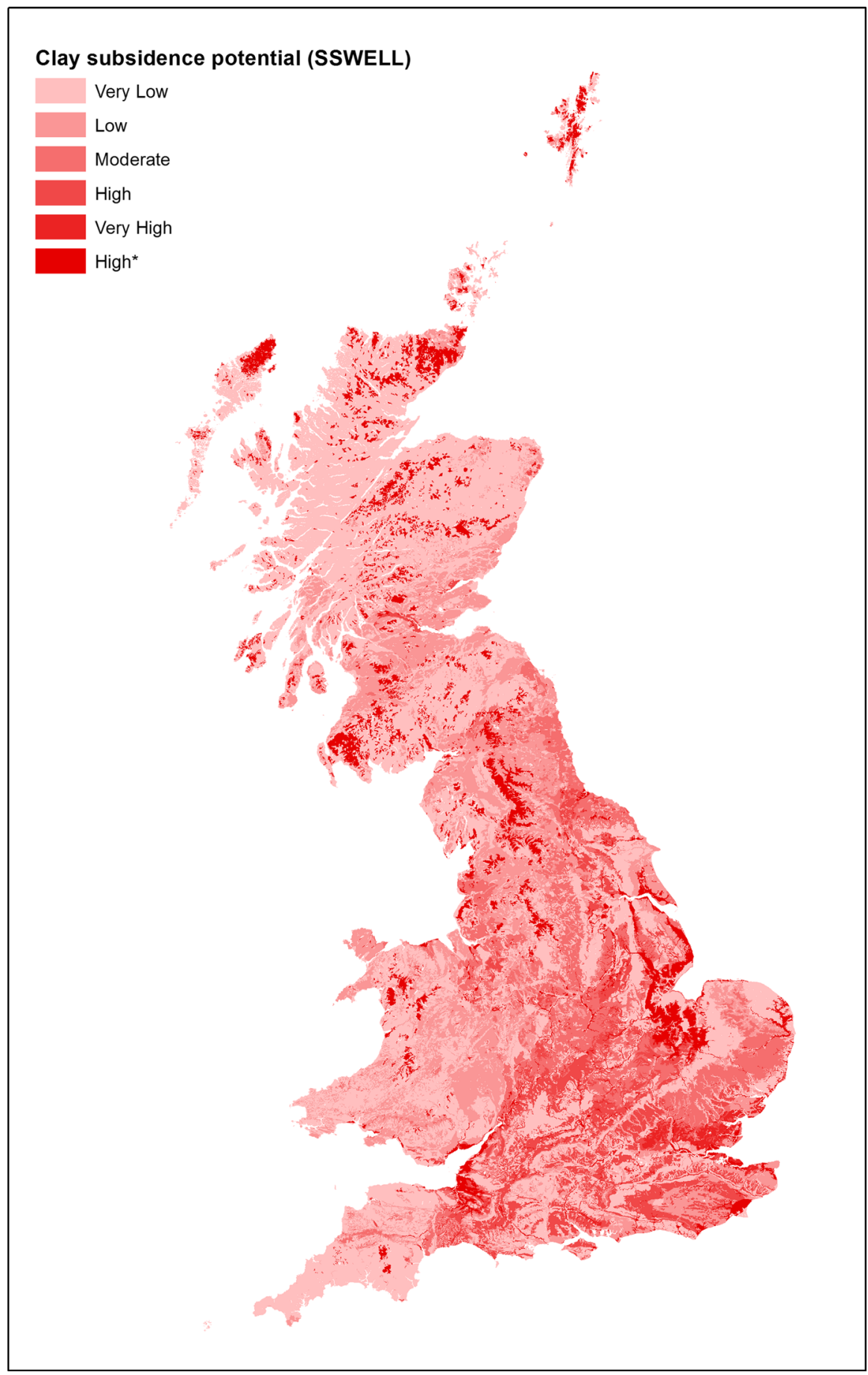

Fig. 2 Clay-related subsidence potential (SSWELL) values for GB (Soils data (England and Wales) C Cranfield University and for the Controller of HMSO 2015; Scottish soils data C James Hutton Institute 2015) 
thematic dataset, constructed through reinterpretation of soil-survey mapping, that provides detailed information on a series of soil-related hazards for GB. Presently, NPD combines historic (1961-75) PSMD and soil shrinkage susceptibility (SSWELL) data to interpret claysubsidence hazard. Soils are allocated six volumetric shrink/swell (SSWELL) classes, based upon laboratory data by Reeve et al. (1980), ranging from 'Very Low' (0) (<3\% volumetric shrinkage) to 'Very High' (6) (>15\% volumetric shrinkage) (Fig. 2). A 'High*' SSWELL class represents soils with alluvial clay or peat at $1 \mathrm{~m}$ depth, but which are only prone to shrinkage when effectively drained to at least $2 \mathrm{~m}$ depth.

To date, climatic extremes within NPD were modelled through the addition of standard deviations around the mean PSMD available to the model. Weaknesses of this approach include both the currency of the now historical time series of the data, and the fact that no effective probabilistic element is employed in the modelling allowing for the management of potential future uncertainty.

For a detailed summary of NPD and associated data, readers are referred to the supplementary material.

\subsection{UKCP09 weather generator}

The standard UKCP09 WG provides simulations of weather sequences on a site-by-site (i.e., $5 \mathrm{~km}$ cell) basis, and so lacks spatial consistency in time over neighbouring grid cells (Jones et al. 2009; Jenkins et al. 2014). Due to specific soil properties extending beyond the $5 \mathrm{~km}$ resolution we adopted a modified version of the UKCP09 stochastic weather generator (WG) (Burton et al. 2013). The WG used builds upon the earlier EARWIG WG (Kilsby et al. 2007) to compile spatially-coherent daily climate values over a 30 year stationary sequence at a $5 \mathrm{~km}^{2}$ resolution for GB. The 30 year sequences included the 'baseline', '2030' and '2050' time periods. Future projections were drawn from the medium emissions scenario, equivalent to the IPCC's (Intergovernmental Panel on Climate Change) SRES A1B scenario (IPCC 2000). As with UKCP09, scenarios did not apply urban land-use corrections.

UKCP09 baseline data were produced to reveal the extent to which the WG is able to match baseline climate calculations with known empirical data (Eames et al. 2012). Figure 3 presents annual average totals of precipitation and potential evapotranspiration for the UKCP09 WGderived baseline (Fig. 3a) and 2050 scenarios (Fig. 3b) which are compared with observed baseline data for GB. In baseline comparisons (Fig. 3a), both observed and UKCP09 WGderived data show the same spread. However, for the 2050s, Fig. $3 \mathrm{~b}$ suggests higher average annual potential evapotranspiration and reduced rainfall. The 30 year WG baseline series was run 100 times based on a different randomly sampled vector of change factors, providing the probabilistic analysis. The future scenarios of 2030 and 2050 represent a higher factor of uncertainty compared with the baseline. Therefore, these scenarios were run 1000 times, based on a differently randomly sampled vector of the 10,000 UKCP09 change factors available to provide the probabilistic analysis.

Unlike its predecessors (UKCIP98 and UKCIP02), UKCP09 does not provide projections of soil moisture. However, the WG does provide daily outputs of rainfall and potential evapotranspiration (PET), fundamental for calculating PSMD (Eq. 1). The following section discusses how projections of PSMD were derived from raw WG data. We then discuss how projected PSMD data were processed and incorporated within the clay-related subsidence geohazard model. The WG was also run to obtain low, medium and high emissions scenario 


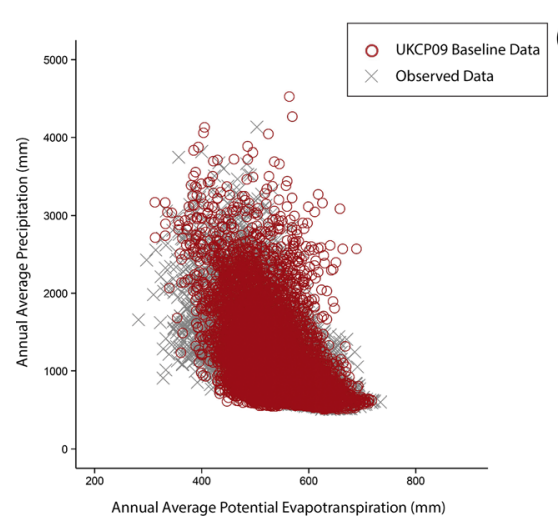

(a)

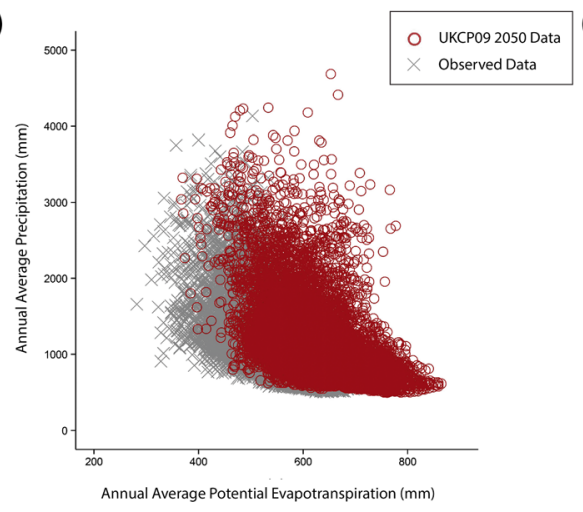

Fig. 3 Variability of GB annual average precipitation and PET (potential evapotranspiration) for the observed historical (1961-1990) data compared to a UKCP09 baseline and b UKCP09 2050 projections. Observed data is derived from $5 \mathrm{~km}$ gridded datasets made available from the Met Office (Perry and Hollis 2005)

PSMD projections for the administrative county of Worcestershire, results being provided in Figure S1 of the Supplementary Material.

\subsection{Computation of soil moisture deficit}

The WG produced substantial output data ( $\approx 50$ Terabytes for GB). Custom software tools were required to process the raw WG files to produce the necessary summary data products required for geohazard modelling. A series of programs were prepared using the Perl scripting language to automate calculation of PSMD values (Fig. 1).

Soil moisture accumulation and loss oscillate over the course of a year. Therefore, a temporal resolution of monthly and annual PSMD were deemed more appropriate than the raw daily data format. Future scenarios represented 1000 daily realisations of climatic parameters which, over a 30 year time series, provided 30,000 realisations of daily climate. PSMD was calculated using the following equation (after Jones and Thomasson 1985):

$$
P S M D=\sum(P P T-P E T)
$$

Where

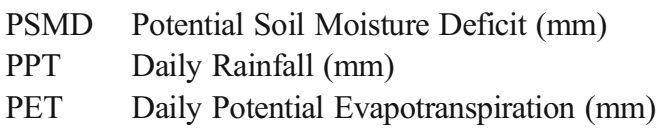

During computation, PSMD was set to 0 each January 1 st and subsequently each day's PSMD (Eq. 2) (if not a surplus) was added to the previous days' PSMD to give an accumulated value. If a surplus of water existed (i.e., PSMD $>0$ ) then it was subtracted from the previous days accumulated PSMD. For consistency with UKCP09 outputs, the mean, and the 10th, 50th and 90th percentiles were calculated, over the WG change factors, for the monthly and annual soil moisture data to represent data uncertainty; the 90th percentile being taken as 'unlikely to be more than', the 10th percentile being 'unlikely to be less than', and the 50th percentile representing the 'central estimate/tendency'. Adopting standardised approaches 
in the representation of UKCP09 uncertainty allows users, who are likely to be familiar with the UK climate projections, to incorporate these modelled data within climate adaptation schemes.

\subsection{Integration of climatic and geohazard models}

The aim of this study was to supplant historical PSMD data in NPD with projections computed from WG data. To achieve this, we spatially referenced the WG-derived PSMD data to the $5 \mathrm{~km}$ WG grid cells (see http://ukclimateprojections-ui.metoffice.gov.uk/ui/docs/grids/wg $5 \mathrm{~km} /$ index.php), intersecting this with the SSWELL data. Clay subsidence hazard was then calculated from the maximum accumulated PSMD and SSWELL using a Python script running within ArcGIS (v. 10.2). Clay subsidence hazard potential in NPD is portrayed with nine classes, ranging from extremely low to extremely high. This process was undertaken for each climatic scenario and for the 10,50 and 90th percentile annual accumulated PSMD.

\section{Results}

\subsection{Potential soil moisture deficit}

Results indicate that PSMD is likely to increase significantly from the baseline through to 2050. The south-east of England is set to undergo the biggest changes, with annual PSMDs based upon the central estimate (50th percentile), set to increase by up to $100 \mathrm{~mm}$ by 2030, and $160 \mathrm{~mm}$ by 2050 (Fig. 4). By contrast, upland UK areas (i.e., Wales, Dartmoor, Exmoor, Lake District and Pennine regions) are unlikely to be affected by these projected climate change scenarios. In these upland areas, PSMD change is unlikely to exceed $20-40 \mathrm{~mm}$ through to 2050. However, during extreme events (i.e., 90th percentile PSMD), higher PSMDs may result (Fig. 4).

It is apparent from Fig. 4 that what may be regarded at the current time as an extreme event (i.e., baseline 90th percentile) is likely to represent PSMD values of a central estimate (50th percentile) by 2030. Moreover, modelled baseline central estimate PSMD values are likely to represent the lower 10th percentile (not likely to be less than) by 2030 and 2050 respectively. Both the 2030 and 2050 scenarios at the 50th and 90th percentiles also indicate that PSMDs are likely to persist through the winter months, carrying deficit across into the following year. However, the data produced by the WG is representative of an independent model year, based upon specific change factors. Therefore, the analysis cannot take into account consecutive years, PSMD being reset to zero each January. It is therefore possible that the models are under-predicting future PSMD and consequent impacts.

\subsection{Weather generator limitations}

Climate models possess a degree of uncertainty, and the downscaling of global circulation models to regional and local-scale models can result in further layers of uncertainty (Coulthard et al. 2012). The usability of climatic projections has been questioned by numerous articles, remaining a key issue in model applications. Dessai and Hulme (2008) argue that prior to UKCP09, UK climate projection models fell broadly within the range of observed climate with the biggest ambiguity occurring for summer rainfall. 

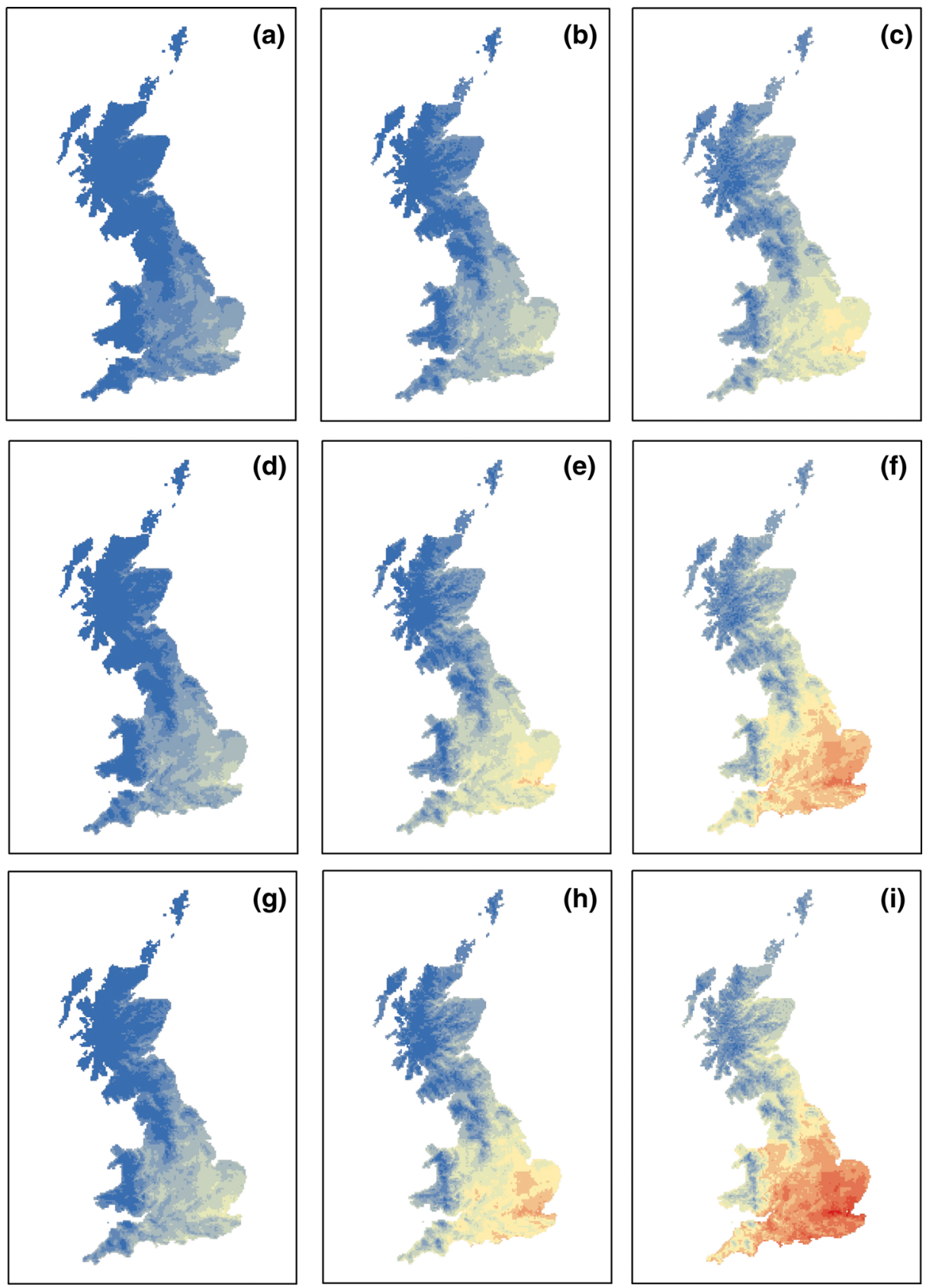

Accumulated PSMD (mm)
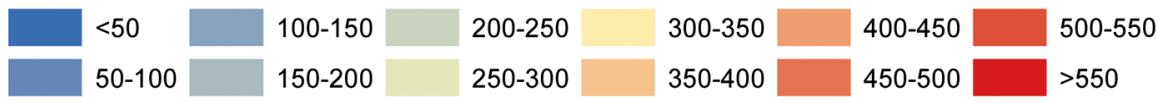

Fig. 4 UKCP09-derived projections of accumulated annual PSMD for GB Baseline (1961-1990) a 10th, b 50th and c 90th percentiles; 2030 (2020-2049) d 10th, e 50th and f 90th percentiles; 2050 (2040-2069) g 10th, h 50th and $\mathbf{i}$ 90th percentiles 
Ekström et al. (2007) argue that the determination of PET is an imperfect science, resulting from a limited knowledge regarding atmosphere-soil feedbacks. Furthermore, PET can be affected by a number of soil properties including, porosity and soil depth. Seneviratne et al. (2010) conducted an extensive review of this, regarding the ability to model accurately soilclimate feedback as being limited by empirical, observed ground data. This is likely to become increasingly apparent as weather station numbers decline (Prior and Perry 2014; Perry and Hollis 2005). Ultimately, improved knowledge in this subject area will reduce inherent uncertainty in climate modelling.

The use of WG-derived outputs must be treated cautiously. Kay and Jones (2012) argue that comparison of WG outputs and empirically-derived baselines will likely not show close agreement as the WG is unable to capture natural climate variability. Moreover, Harding et al. (2014) argue that the interpolation of empirical weather data presents its own uncertainty and bias. We address uncertainty inherent in the WG by providing a range of probable scenarios for clay-subsidence hazard (Fig. 5).

\subsection{Outlook for clay-related subsidence potential}

Figure 5 shows clay-related subsidence hazard modelled for the baseline, 2030, and 2050 timeperiods at the 10th, 50th and 90th percentiles. The south-east of England will become increasingly prone to clay-related subsidence through to 2050, resulting from high PSMDs coupled with extensive clay-rich soils with mineralogy prone to shrink-swell activity. The north-east of England is also likely to incur increased susceptibility. Conversely, Scotland and Wales are unlikely to see substantive increases in clay-related subsidence hazard. Although many soil types known to be prone to moisture-related shrinkage exist (Fig. 2), PSMDs are not set to change significantly through to 2050. Exceptions to this are the areas around the Firth of Forth and the River Tay estuaries in Scotland where the hazard potential of the shrinkswell prone alluvial soils changes from a medium low to a high/very high class by 2050.

Figure 6 details the land area of each subsidence hazard class for the baseline, 2030 and 2050 scenarios. By the 2050s, $12 \%$ of the land area of GB will be at extremely high or very high hazard potential for clay related subsidence, comparable to the $7 \%$ of land area for the 1961-1990 baseline. The apparent diminishing of the high class is a consequence of higher PSMDs, causing redistribution of values to the very high and extremely high classes. Approximately $75 \%$ of the land area in Great Britain is underlain by soils of low to extremely low likelihood of clay-related subsidence hazard for the baseline period (i.e., $<5 \%$ volumetric shrinkage potential) and is only set to decrease to $73 \%$ by 2050 (Fig. 6). The texture and mineralogy of these soils determine that they will not undergo volumetric change under differing moisture conditions as PSMD changes occur. Significant mineralogical change will not occur within the timeframe considered in this paper (i.e., up to 2069), therefore, these soils remain at low hazard of clay shrinkage.

\section{Discussion and conclusions}

We have developed a method for processing UKCP09 high-resolution climate projection data to produce probabilistic scenarios of PSMD based on the medium emission (SRES A1B) scenario. Resultant PSMD scenarios were incorporated within a soil-related geohazard model. The outcome has been the production of a novel, national-scale thematic dataset revealing 

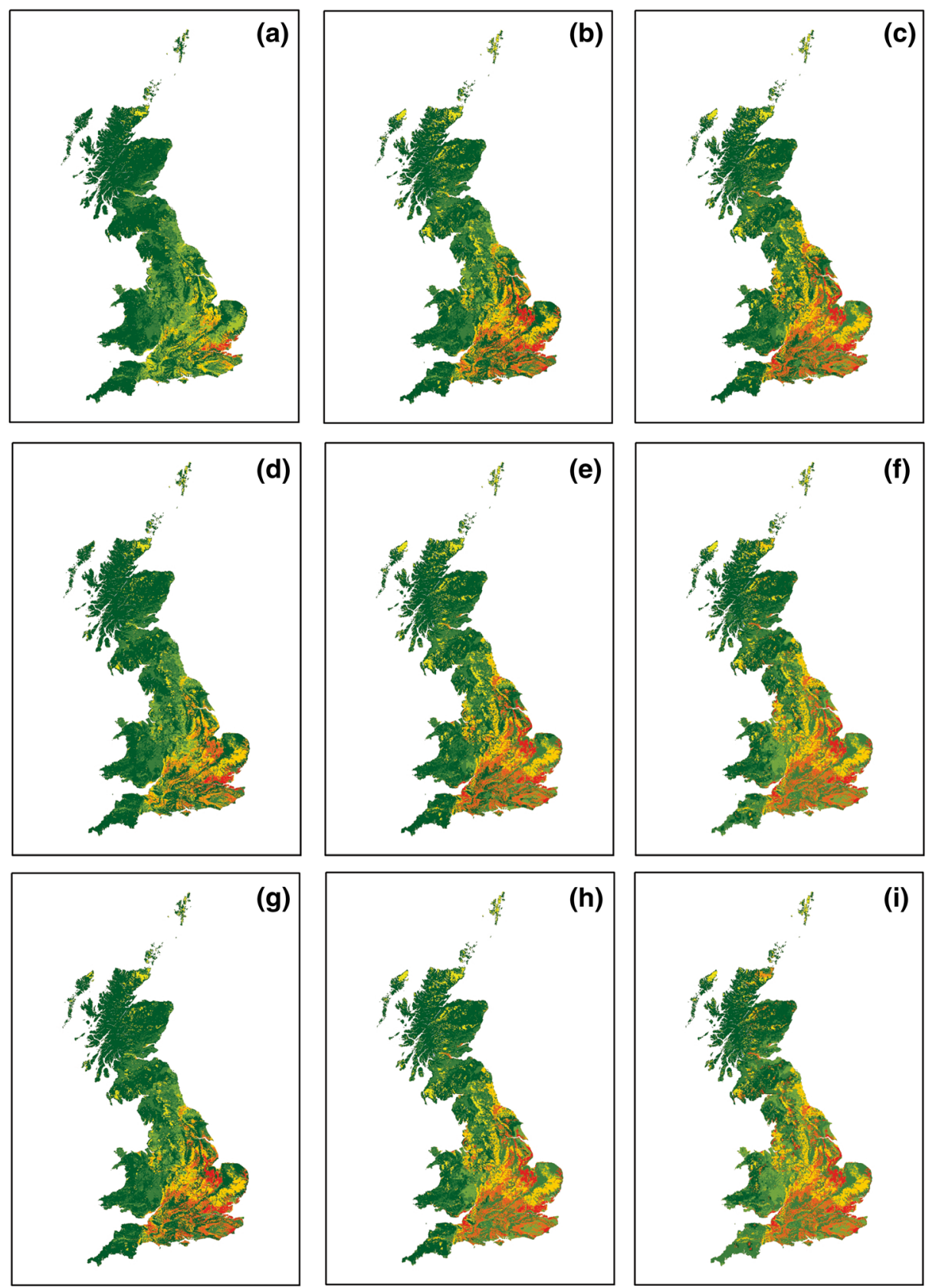

Hazard Class $\square$ Extremely Low $\square$ Very Low $\square$ Low $\square \quad$ Medium Low $\square$ Medium $\square$ Medium High $\square$ High $\square$ Very High $\square$ Extremely High

Fig. 5 Projections of GB clay-related subsidence hazard for Baseline (1961-1990) a 10th, b 50th and c 90th percentiles; 2030 (2020-2049) d 10th, e 50th and f 90th percentiles; 2050 (2040-2069) g 10th, h 50th and i 90th percentiles. (Soils data (England and Wales) (C) Cranfield University and for the Controller of HMSO 2015; Scottish soils data (C) James Hutton Institute 2015) 


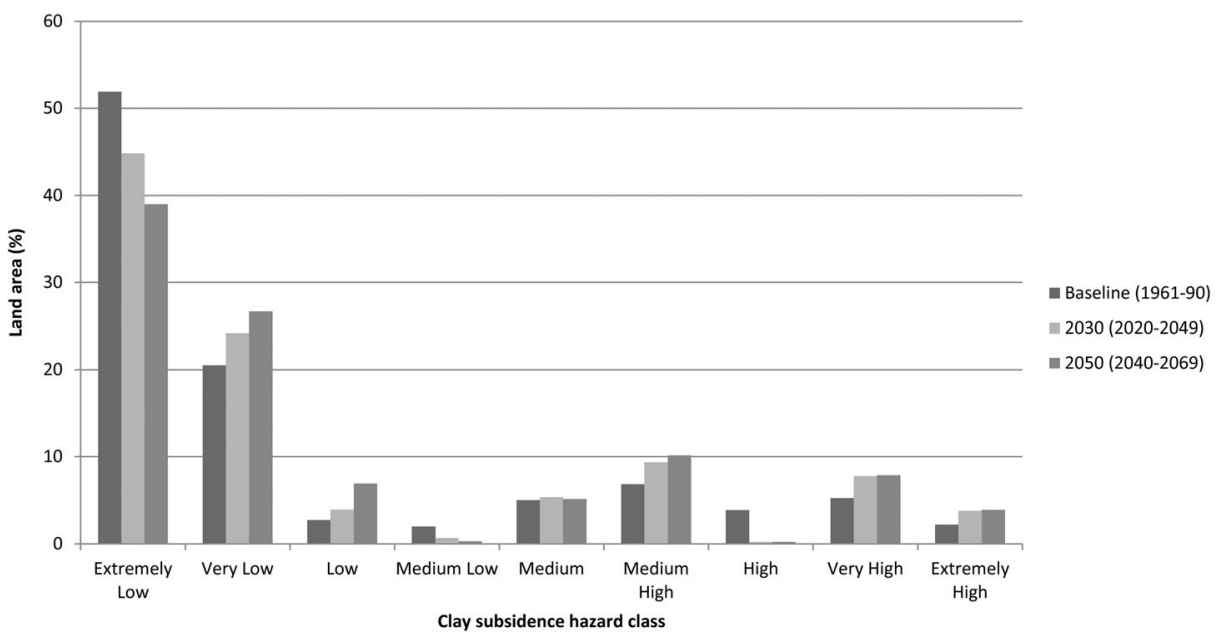

Fig. 6 Percentage of GB land area by clay subsidence hazard class

spatial and temporal distribution, alongside inherent uncertainty, of potential clay-related subsidence across a range of future time-periods. This advancement in the spatio-temporal understanding of clay-related subsidence hazard potential will bring benefits to organisations and stakeholders with long term interests. Projections suggest that clay-related subsidence will become more common in GB. Particular concerns centre on southeast England, where modelled PSMD indicates a substantial increase through to 2050 (Fig. 4) compared to the baseline. This could indicate areas at a current medium hazard of clay-related subsidence potentially becoming exposed to very high and extremely high hazard by 2050 (Fig. 5).

France's drought of 2003 resulted in a number of subsidence claims arising from a lack of preparedness and adaptation (Corti et al. 2011). The fact that GB's built environment suffers currently from degradation and/or failure as a result of clay subsidence indicates that as a society, GB is not wholly resilient to this hazard. The projections shown in this paper suggest that the built environment and critical infrastructure of England, Scotland and Wales are likely to become further exposed to clay-related subsidence at higher frequency and magnitude, through to 2050 and beyond. Damage is likely to affect, in particular, shallow-founded structures and buried infrastructure networks, particularly where mitigation practices are not in place and/or understood. Subsidence hazard could also affect the material consideration of house valuations (Wynn and Hardiment 2001). Crilly's (2001) analysis of a subsidence damage database argues that there 'are no reasons to be concerned over current minimum depth requirements' of building foundations. However, Hawkins (2013) argues that in drought years, evidence of shrinkage can reach depths $>2.5 \mathrm{~m}$ below ground level which is beyond current minimum foundation depth recommendations of $0.9 \mathrm{~m}$ (NHBC 2008). In Rodda and Marsh's (2011) assessment of the 1975-76 drought, the future projections of PSMD in both 2030 and 2050 (Fig. 4) show similarities to previous events, that resulted in extensive damage. This is especially so where PSMD, even at the 10th percentile, is still present in the winter months (i.e., November and December) allowing it to be carried over into the following years (Fig. 4). Similarly, an analysis of the UK drought in 2003, showed modelled values of PSMD are likely to be much higher than those of the 1962-2003 average depicted (Marsh 2004). The assessments detailed in this paper may therefore provoke consideration as to whether to 
reassess construction practices in regard to helping facilitate significant changes towards riskmanagement-based approaches to clay-related subsidence.

Since the 1975-76 drought, extensive reforms in UK planning policy have led to better design practices, related to the construction of new domestic and commercial property foundations. This has helped mitigate the risk of clay-related subsidence on properties since this time. Planning Policy Guidance 14 (PPG14) is one example of this, advising local planning authorities to identify areas where the potential impact of subsidence on development could be realised (DTLR 2002). Despite this, Wilson (2006) identified that only one of 14 local climate impact studies surveyed recognised subsidence as a threat to the built environment, perhaps due to its chronic rather than acute characteristic.

Planning policy for UK infrastructure development appears fragmented in addressing both climate change and geohazards. A series of National Policy Statements (NPS) are available (see: http://infrastructure.planninginspectorate.gov.uk/legislation-and-advice/national-policystatements), covering the energy, transport and water, waste water and waste infrastructure sectors. However, water supply in itself currently does not have an NPS, with no stated plans to implement one. For example, the wastewater NPS discusses the impact of leaks on soil quality, but not the impact that soil processes could have on fracture rates of this infrastructure as reported by Owen et al. (1992). Conversely, gas and electricity NPSs provide more detail on potential soil effects to the respective infrastructure networks. GB infrastructure represents extremely complex networks that are aging, some assets reported as being $>100$ years in age, and which are constructed from a range of materials. Consequently, networks are susceptible to climate change and geohazards, further exacerbated by increasing public demand (Pritchard et al. 2014). Moreover, the increasing interconnection and spatial proximity of networks can mean failure of a particular infrastructure asset leading to failure(s) in another (Rogers et al. 2012). The high-resolution of these projections can enable stakeholders at the local, regional and national scale identify where clay-related subsidence may affect assets in future decades. The incorporation of climate change adaptation strategies and tools, relating to infrastructure asset management, is prudent for long-term asset risk management and ultimately reducing costs and disruptions caused by asset failures. Therefore, we recommend that the NPSs for infrastructure resilience be amended to more fully incorporate potential climate change and environmental vulnerabilities.

Harding et al. (2014) argue that end-users of climate model data are predominantly interested in the magnitude of change that is likely to be experienced. The probabilistic projections of clay subsidence provided (Fig. 5) should therefore be used in their entirety (i.e., 10th, 50th and 90th percentiles) when forming part of resilience planning and/or climate risk assessments. Local factors such as significant vegetation can act to modify these projections. An understanding of all the factors at play will help ensure construction of a built environment with resilience to cope with the majority of extreme events, but which is ultimately dependent on individual risk appetites. A forward looking risk management approach to clay-related subsidence will require a range of subsidence scenarios to avoid potential surprises in future climates. As climate models evolve and improve, this methodology can integrate appropriate data for assessment of clay-related subsidence hazard. Mastrandrea et al. (2010) argue that decision makers are interested in information which clearly depicts climate change risks. The thematic results presented here, are aimed primarily at non soil-scientists and are presented in an easily understandable format, to encourage evidence-based decision making. 
Due to time and data constraints we were not able to assess the entire range of emissions scenarios available in UKCP09. These will be considered in future work further to the regional example in Figures S1 and S2 in the Supplementary Material. We anticipate that the integration of real-time soil-moisture monitoring with remotely sensed data (e.g., SMOS and the recently launched SMAP) could provide users with predictive tools to consider where clay-related subsidence and subsequent failure(s) or degradation are likely to occur in real-time. This approach would prove beneficial for asset management and maintenance scheduling for vulnerable components of the built environment and critical infrastructure. For this assessment, we have not accounted for local vegetation effects, for example high water demand trees. However, when using these maps, users should be aware of the potential for proximal high water-demand trees to result in higher localised PSMD, promoting higher clay subsidence hazards than those reported here. Furthermore, although the research scope of this paper has been primarily directed at clay-related geohazard modelling, soilmoisture assessments have many other research applications, for example in water resource management, flood control, domestic building construction and other agricultural sector applications.

Acknowledgments The research reported in this paper is part of the UK 'Infrastructure Transitions Research Consortium' (ITRC), funded by the Engineering and Physical Sciences Research Council (EPSRC) under programme grant EP/I01344X/1. The research also received support from Cranfield University's EPSRCfunded Impact Acceleration Account (EP/K503927/1). The authors thank the James Hutton Institute for providing Scottish soils data. The authors are grateful to: V. Glenis (Newcastle University) for continued support and guidance pertaining to the weather generator application, R. Jones and C. Keay for providing historic potential evapo-transpiration data. Observed climatic data was made available with permission from the UK Met Office.

Open Access This article is distributed under the terms of the Creative Commons Attribution 4.0 International License (http://creativecommons.org/licenses/by/4.0/), which permits unrestricted use, distribution, and reproduction in any medium, provided you give appropriate credit to the original author(s) and the source, provide a link to the Creative Commons license, and indicate if changes were made.

\section{References}

Blenkinsop S, Hallett SH, Truckell I, Fowler HJ (2010) The CREW project: towards a toolkit for the use of probabilistic climate change projections. BHS Third International Symposium, Role of Hydrology in Managing Consequences of a Changing Global Environment, Newcastle. Available at http://www. hydralab.eu/participant-area/assets/documents/test.pdf. Accessed 24 Aug 2015

Borgomeo E, Hall JW, Fung F, Watts G, Colquhoun K, Lambert C (2014) Risk-based water resources planning: incorporating probabilistic nonstationary climate uncertainties. Water Resour Res 50:6850-6873. doi:10. 1002/2014WR015558

Brook D, Marker B (2008) Planning for development on land that is potentially prone to subsidence in England. Q J Eng Geol Hydrogeol 41:403-408. doi:10.1144/1470-9236/07-205

Burton A, Fowler H, Blenkinsop S, Kilsby CG (2010) Downscaling transient climate change using a NeymanScott rectangular pulses stochastic rainfall model. J Hydrol 381:18-32

Burton A, Glenis V, Jones M, Kilsby C (2013) Models of daily rainfall cross-correlation for the United Kingdom. Environ Model Softw 49:22-33

Cabinet Office (2011) Keeping the country running: natural hazards and infrastructure. A guide to improving the resilience of critical infrastructure and essential services. Cabinet Office, London. https:/www.gov.uk/ government/uploads/system/uploads/attachment_data/file/61342/natural-hazards-infrastructure.pdf. Accessed 22 Mar 2015

Christierson BV, Vidal JP, Wade SD (2012) Using UKCP09 probabilistic climate information for UK water resource planning. J Hydrol 424-425:48-67

Clarke D, Smethurst JA (2010) Effects of climate change on cycles of wetting and drying in engineered clay slopes in England. Q J Eng Geol Hydrogeol 43:473-486 
Corti T, Wuest M, Bresch D, Seneviratne SI (2011) Drought-induced building damages from simulations at regional scale. Nat Hazards Earth Syst Sci 11:3335-3342

Coulthard TJ, Ramirez J, Fowler HJ, Glenis V (2012) Using the UKCP09 probabilistic scenarios to model the amplified impact of climate change on drainage basin sediment yield. Hydrol Earth Syst Sci 16:4401-4416

Crichton D (2001) The implications of climate change for the insurance industry. Building Research Establishment, Watford

Crilly M (2001) Analysis of a database of subsidence damage. Struct Surv 19:7-15

Defra (Department for Environment, Food and Rural Affairs) (2012) UK climate change risk assessment: government report. The Stationery Office, London. Available at: https:/www.gov.uk/government/uploads/ system/uploads/attachment_data/file/69487/pb13698-climate-risk-assessment.pdf. Accessed 15 Nov 2013

Dessai S, Hulme M (2008) How do UK climate scenarios compare with recent observations? Atmos Sci Lett 9: 189-195. doi:10.1002/asl.197

DTLR (2002) Planning policy guidance note 14 development on unstable land, Annex 2: subsidence and planning. Department for Transport, Local Government and the Regions. HMSO, London

Eames M, Kershaw T, Coley D (2012) A comparison of future weather created from morphed observed weather and created by a weather generator. Build Environ 56:252-264

Ekström M, Jones PD, Fowler HJ, Lenderink G, Buishand TA, Conway D (2007) Regional climate model data used within the SWURVE project-1: projected changes in seasonal patterns and estimation of PET. Hydrol Earth Syst Sci 11:1069-1083

Forster A, Culshaw M (2004) Implications of climate change for hazardous ground conditions in the UK. Geol Today 20:61-66. doi:10.1111/j.1365-2451.2004.00442.x

Hallett SH, Keay C, Jarvis MG, Jones RJA (1994) INSURE: subsidence risk assessment from soil and climate data. Proceedings of the Association for Geographic Information (AGI) National Conference: Markets for Geographic Information. Association for Geographic Information 16.2.1-16.2.7

Harding AE, Rivington M, Mineter M, Tett SFB (2014) Agro-meteorological indices and climate model uncertainty over the UK. Clim Chang 128:113-126. doi:10.1007/s10584-014-1296-8

Harrison AM, Plim JFM, Harrison M, Jones LD, Culshaw MG (2012) The relationship between shrink-swell occurrence and climate in south-east England. Proc Geol Assoc 123:556-575

Hawkins A (2013) Some engineering geological effects of drought: examples from the UK. B Eng Geol Environ 72:37-59

IPCC (2000) IPCC Special Report on Emissions Scenarios - A summary for Policymakers. In: Nakicenovic N, Swart R (eds). Special Report on Emissions Scenarios: A Special Report of Working Group III of the Intergovernmental Panel on Climate Change Cambridge University Press, Cambridge. Available at: https:// www.ipcc.ch/pdf/special-reports/spm/sres-en.pdf. Accessed 19 Feb 2015

Jenkins G, Murphy J, Sexton D, Lowe J, Jones P, Kilsby C (2009) UK climate projections: briefing report. Available at: http://ukclimateprojections.metoffice.gov.uk/media.jsp?mediaid=87867\&filetype=pdf. Accessed 13 Dec 2014

Jenkins K, Hall J, Glenis V, Kilsby C, McCarthy M, Goodess C, Smith D, Malleson N, Birkin M (2014) Probabilistic spatial risk assessment of heat impacts and adaptations for London. Clim Chang. doi:10.1007/ s10584-014-1105-4

Jones RJA, Thomasson A (1985) An agroclimatic databank for England and Wales, vol 16, Technical Monograph. Soil Survey of England and Wales, Harpenden

Jones P, Kilsby C, Harpham C, Glenis V, Burton A (2009) UK Climate Projections science report: projections of future daily climate for the UK from the weather generator. University of Newcastle, Newcastle, UK. Available at: http://ukclimateprojections.metoffice.gov.uk/media.jsp?mediaid=87848\& filetype=pdf.. Accessed 13 Dec 2014

Kay AL, Jones RG (2012) Comparison of the use of alternative UKCP09 products for modelling the impacts of climate change on flood frequency. Clim Chang 114:211-230

Kilsby CG, Jones PD, Burton A, Ford AC, Fowler HJ, Harpham C, James P, Smith A, Wilby RL (2007) A daily weather generator for use in climate change studies. Environ Model Softw 22:1705-1719. doi:10.1016/j. envsoft.2007.02.005

Knox J, Morris J, Hess T (2010) Identifying future risks to UK agricultural crop production: putting climate change in context. Outlook Agric 39:249-256

Marsh TJ (2004) The UK drought of 2003: a hydrological review. Weather 59:224-230. doi:10.1256/wea.79.04

Mastrandrea MD, Heller NE, Root T, Schneider SH (2010) Bridging the gap: linking climate-impacts research with adaptation planning and management. Clim Chang 100:87-101. doi:10.1007/s10584-010-9827-4

NHBC (2008) Minimum foundation depths in clay soil. Technical Guidance 4.4/03, National House Building Council. http://www.nhbc.co.uk/Builders/Technicaladviceandsupport/TechnicalGuidance/44/ filedownload,37165,ee.pdf. Accessed 27 July 2015 
Owen RC, Rees SW, Thomas HR (1992) Soil moisture studies and buried pipes. In: Geddes JD (ed) Ground movements and structures. Pentech Press, London, pp 142-153

Perry M, Hollis D (2005) The generation of monthly gridded datasets for a range of climatic variables over the UK. Int J Climatol 25:1041-1054

Prior MJ, Perry MC (2014) Analyses of trends in air temperature in the United Kingdom using gridded data series from 1910 to 2011. Int J Climatol 34:3766-3779

Pritchard OG, Farewell TS, Hallett SH (2014) Soil impacts on UK infrastructure: current and future climate. Proc Inst Civ Eng Eng Sustain 167:170-184. doi:10.1680/ensu.13.00035

Pritchard OG, Hallett SH, Farewell TS (2015) Soil geohazard mapping for improved asset management of UK local roads. Nat Hazards Earth Syst Sci Discuss 3:3151-3180. doi:10.5194/nhessd-3-3151-2015

Pugh R (2002) Some observations on the influence of recent climate change on the subsidence of shallow foundations. Proc Inst Civ Eng Geotech Eng 155:23-25

Rawlins B, Harris J, Price S, Bartlett M (2013) A review of climate change impacts on urban soil functions with examples and policy insights from England, UK. Soil Use Manag. doi:10.1111/sum.12079

Reeve M, Hall D (1978) Shrinkage in clayey subsoils of contrasting structure. J Soil Sci 29:315-323

Reeve M, Hall D, Bullock P (1980) The effect of soil composition and environmental factors on the shrinkage of some clayey British soils. J Soil Sci 31:429-442

Rodda JC, Marsh TJ (2011) The 1975-76 Drought - a contemporary and retrospective review. Centre for Ecology and Hydrology. http://www.ceh.ac.uk/data/nrfa/nhmp/other_reports/CEH_1975-76_Drought_ Report_Rodda_and_Marsh.pdf. Accessed 5 Feb 2015

Rogers CDF, Bouch CJ, Williams S, Barber ARG, Baker CJ, Bryson JR, Chapman DN, Chapman L, Coaffee J, Jefferson I, Quinn AD (2012) Resistance and resilience - paradigms for critical local infrastructure. Proc Inst Civ Eng Munic Eng 165:73-84. doi:10.1680/muen.11.00030

Royse KR (2011) The handling of hazard data on a national scale: a case study from the British Geological Survey. Surv Geophys 32:753-776

Sanders C, Phillipson M (2003) UK adaptation strategy and technical measures: the impacts of climate change on buildings. Build Res Inf 31:210-221

Seneviratne SI, Corti T, Davin E, Hirschi M, Jaeger EB, Lehner I, Orlowsky B, Teuling AJ (2010) Investigating soil moisture-climate interactions in a changing climate: a review. Earth-Sci Rev 99:125-161

Wilson E (2006) Adapting to climate change at the local level: the spatial planning response. Local Environ 11: 609-625. doi:10.1080/13549830600853635

Wynn P, Hardiment G (2001) Mortgage valuation report forms and the identification of subsidence. Struct Surv 19:15-20 